\title{
Das Baltikum: Stabilität in der Instabilität. Die fünften Parlamente in Estland, Lettland und Litauen
}

\author{
Axel Reetz
}

Die fünften Parlamentswahlen in den drei Republiken des Baltikums seit der Unabhängigkeit von der Sowjetunion könnten als Routine bezeichnet werden. In keinem der drei Länder hat sich die politische Landschaft in überraschender Weise verändert und weicht von früheren Beobachtungen ab. Zwar werden Estland, Lettland und Litauen nach wie vor als Region gesehen, aber in Europa setzt sich inzwischen die Kenntnis ihrer Unterschiedlichkeit durch. Ob die drei Staaten gemeinsam oder getrennt behandelt werden sollten, ist regelmäßig Anlass zur Diskussion. Es gibt gute Gründe für beide Ansätze.

Im Jahre 2008 stehen dafür beispielhaft zwei weltpolitische Ereignisse: die Finanzkrise und der Krieg im Kaukasus zwischen Russland und Georgien. Während bezogen auf dieses Thema die baltischen Republiken unisono mit einer scharfen Verurteilung des russischen Vorgehens reagierten und sich ebenso gemeinsam mit einer schärferen Reaktion in der NATO nicht durchsetzen konnten, so zeigen die Folgen der Finanzkrise die Konsequenzen unterschiedlicher Politiken in Estland, Lettland und Litauen. Lettland ist besonders betroffen von der Krise.

Die Unterschiedlichkeit der Politischen Kulturen und der auch durch Einzelpersonen geprägten Entwicklung der Jahre nach der Unabhängigkeit ist eine zunehmend triviale Feststellung. Gleichzeitig sind die drei kleinen Länder international wie auch in der NATO und der EU, wo sie seit 2004 Mitglied sind, bei weitem nicht von so großer Bedeutung. Ähnlichkeiten liegen darin, dass von einer politischen Routine wie in den etablierten Demokratien noch nicht die Rede sein kann. Und auch von den anderen inzwischen großteils in die EU aufgenommenen postsozialistischen Staaten unterscheiden sie sich in ihrer noch ausgeprägteren Instabilität. Seit 1990, respektive seit den ersten Wahlen nach der Unabhängigkeit 1992 und 1993 hat bislang keine einzige Regierung über eine volle Wahlperiode regiert. Zwar konnten die regierenden Koalitionen in Lettland 2006 und in Estland 2007 sich vom Wahlergebnis im Amt bestätigt sehen, doch in beiden Fällen zogen es die Parteien der Regierungschefs vor, das Bündnis zu verändern, den Partner zu wechseln - Estland oder die Koalition zu erweitern - Lettland.

Als wohl eher zufällige Gemeinsamkeit wurde das Präsidentenamt von Oktober 2006 bis Juli 2007 in allen drei Staaten des Baltikums mit Rückkehrern aus dem Exil besetzt: in Estland Toomas-Hendrik Ilves, in Lettland Vaira Vike-Freiberga und in Litauen Valdas Adamkus. Ilves war im Herbst 2006 gewählt worden, ein gutes halbes Jahr vor Ende von Vike-Freibergas zweiter Amtszeit.

\section{Estland}

\subsection{Parteiensystem}

Das Parteiensystem Estlands beginnt sich zu konsolidieren. Die Vaterlandsunion, ihrerseits ein Zusammenschluss aus Vaterland und Unabhängigkeitspartei vereinigte sich im April 
2006 mit Res Publica. Diese Partei war 2002 als Hoffnungsträger im Kampf gegen eine als korrupt empfundene politische Elite seit 1994 die erste sehr erfolgreiche Parteineugründung gewesen. Die Vaterlandsunion entwickelt sich damit, vergleichbar zur CDU, zu einem Magneten im bürgerlich-konservativen Lager.

2007 war die Wahlbeteiligung mit etwa 61 Prozent gering. Das sei durchaus auch ein Ausdruck allgemeiner Zufriedenheit, mutmaßt Spolitis. ${ }^{1}$

Die ablehnende Haltung gegenüber den Politikern beider Parteien bei einem Teil der konservativen Wählerschaft führte allerdings zu einer kleinen Bereicherung des Parteiensystems. Die Grünen, die 1992 mit einem Abgeordneten im Parlament vertreten gewesen waren, kehrten in Fraktionsstärke zurück. Allerdings ist diese neue politische Kraft parteihistorisch nicht vollständig deckungsgleich mit der vormaligen. Umweltschutz hatte in der Endphase der Sowjetunion als Protest gegen deren Politik einen nationalen Charakter. Inwieweit der Erfolg der Grünen von 2006 inzwischen auch auf einer postmaterialistischen Strömung basiert, ist einstweilen unsicher. ${ }^{2}$

Gleichzeitig ist in Abwesenheit einer wirklichen Linken dieses politische Lager weiter in Bewegung. Die Parteien neben dem nationalkonservativen und dem liberalen Lager besetzen linke Positionen kaum dauerhaft und überzeugend und tragen sogar, regelmäßig an regierenden Koalitionen beteiligt, eine entgegengesetzte Politik mit. Dies gilt besonders für die seit Februar 2004 als Sozialdemokraten auftretenden früheren Moderaten, die sich mit einem Erfolg bei den Europawahlen desselben Jahres stabilisieren konnten. Die Volksunion wiederum hat seit dem Ende der Amtszeit von Präsident Arnold Rü̈ütel 2006 keine populären Spitzenpolitiker mehr. Der neue Parteichef Villu Reiljan musste sich wegen eines Immobilienskandals und der anschließenden Aufhebung seiner Abgeordnetenimmunität aus der Politik zurückziehen. Die aus Rü̈̈tels Agrarierpartei hervorgegangene politische Kraft war besonders auf dem Lande beliebt; doch dort verschwindet die Wählerschaft einerseits durch die Abwanderung der Jugend in die Städte, andererseits wegen eines sich in Estland auch auf dem Lande einstellenden Wohlstandes bei gleichzeitig rückgängiger Bedeutung der Landwirtschaft.

Die Zentrumspartei gehört schon dem Namen nach nicht zur politischen Linken, ist jedoch während der vergangenen Jahre am ehesten eine Partei gewesen, die mit deutlich sozialdemokratischen Losungen um Wähler geworben hat. Sie ist nach wie vor eine starke politische Kraft, die mit der Reformpartei in Umfragen um die Spitzenposition ringt, aber vorwiegend wegen ihres Parteivorsitzenden Edgar Savisaar, den die politische Konkurrenz als enfant terrible betrachtet, und die durch Anti-Koalitionen ${ }^{3}$ von der Macht ferngehalten wird. Dies geht einerseits zurück auf Savisaars Zeit als Regierungschef der Volksfront 1990 bis 1992 und wurde noch einmal virulent während des Aufzeichnungsskandals 1995. Savisaars Malus besteht außerdem in der Unterstützung durch das russischsprachige Elektorat.

1 Vgl. Veiko Spolītis, Igaunijas vēlēšanu pragmatisms?, in: Diena vom 28. Februar 2007.

2 Vgl. ders., Taking Root in Unfertile Soil: The Growth of the Estonian Green Parties, in: HeinrichBöll-Stiftung (Hrsg.), Green Identity in a Changing Europe, Brüssel 2008, S. 66 - 71.

3 Vgl. Axel Reetz, From Personality to Anti-Coalition. Exclusion as a Principle of Coalition Making. Part I, in: The Monthly Survey of Baltic and Post-Soviet Politics, 108. Jg. (2001/2002), H. 6, S. 137 - 144; ders., From Personality to Anti-Coalition. Exclusion as a Principle of Coalition Making. Part II, in: The Monthly Survey of Baltic and Post-Soviet Politics, 109. Jg. (2001/2002), H. 7, S. $134-144$. 


\begin{tabular}{|l|c|c|}
\hline Tabelle 1: Ergebnis der Parlamentswahl in Estland vom 4. März 2007 \\
\hline Partei & $\begin{array}{c}\text { Stimmen } \\
\text { (in Prozent) }\end{array}$ & Mandate \\
\hline Reformpartei (Reformierakond) & 27,8 & 31 \\
Zentrumspartei (Keskerakond) & 26,1 & 29 \\
Union von Vaterland und Res Publica (Erakond Isamaa ja Res Publica Liit) & 17,9 & 19 \\
Sozialdemokratische Partei (Sotsiaaldemokraatlik Erakond) & 10,6 & 10 \\
Partei der Grünen Estlands (Eestimaa Roheliste Erakond) & 7,1 & 6 \\
Volksunion Estlands (Eestimaa Rahvaliit) & 7,1 & 6 \\
Estnische Christliche Demokraten (Eesti Kristlikud Demokraadid) & 1,7 & \\
Verfassungspartei (Konstitutsioonierakond) & 1,0 & \\
Unabhängigkeitspartei (Iseseisvuspartei) & 0,2 & \\
Russische Partei in Estland (Vene Erakond Eestis) & 0,2 & \\
Linkspartei (Vasakpartei) & 0,1 & \\
Einzelkandidaten & 0,1 & \\
\hline Quelle: http://vvk.ee/past-elections/riigikogu-parliament-elections/riigikogu-elections-2007 (Abruf am \\
17. Januar 2011).
\end{tabular}

Die Oppositionsrolle der Zentrumspartei änderte sich erst infolge des Niedergangs der Partei Res Publica, deren Regierung im April 2005 scheiterte. Dem lagen sowohl innere Konflikte zugrunde als auch der Streit mit dem kleineren Koalitionspartner, der Reformpartei, über Korruptionsvorwürfe. Nachdem die Reformpartei die Koalition aufgekündigt hatte, benötigte sie einen neuen Partner, wobei aus rein arithmetischen Gründen nur die Zentrumspartei die nötigen Mehrheiten liefern konnte. Immerhin gelang es Andrus Ansip von der Reformpartei, als kleinerer Partner den Ministerpräsidenten zu stellen.

\subsection{Regierungen}

Das Wahlergebnis vom März 2007 bestätigte die annähernd gleiche Zustimmung der Wählerschaft zu Reformpartei und Zentrumspartei. Die regierende Koalition unter Ansip hätte also fortgesetzt werden können. Doch dies war nicht zu erwarten, da die Zentrumspartei nicht Wunschpartner des Wahlsiegers und auch ohne andere Bündnisoptionen war. Ansip verhandelte wenig überraschend mit seinem früheren Koalitionspartner, der inzwischen mit Vaterland fusionierten Res Publica. Gemeinsam blieben beide Parteien jedoch ein Mandat unter der absoluten Mehrheit. Eine Einigung mit der viertstärksten Fraktion, der Sozialdemokratischen Partei, erinnerte an eine Neuauflage der Dreierkoalition (Kolmikliit) unter Mart Laar zwischen 1999 und 2002, die seit der Wiedererlangung der Unabhängigkeit 1991 die am längsten bestehende Regierung war. Die Koalitionsverhandlungen gestalteten sich jedoch unter anderem deshalb schwierig, weil der frühere zweimalige Regierungschef Laar gern Außenminister geworden wäre. Die Reformpartei wollte dafür aber ihren Amtsinhaber Urmas Paet nicht opfern. Auch sollte nicht der Eindruck entstehen, dass quasi Personen von gestern wieder in politische Spitzenpositionen zurückkehren. Das Bündnis mit den Sozialdemokraten kam zustande, aber Laar verweigerte sich schließlich allen anderen angebotenen Ämtern und blieb Abgeordneter. 
Die Bildung einer Regierung wurde außerdem durch die Gespräche mit den Grünen verlangsamt. Auch wenn die Dreierkoalition mit 60 Abgeordneten von 101 eine Mehrheit haben würde, erschien diese dem Regierungschef angesichts häufiger Fraktionswechsel in den vergangenen Jahren und vorprogrammierten Konflikten zwischen den drei Partnern nur bedingt komfortabel. Sie war allerdings für Ansip letztlich doch sicher genug, um den Forderungen der Grünen nach dem Umweltministerium nicht nachzugeben und damit den Rückzug dieser Partei aus den Gesprächen zu provozieren.

Im Frühjahr 2009 ließen die Sozialdemokraten dann einen Konflikt um die Arbeitsgesetzgebung vor dem Hintergrund der Finanzkrise eskalieren und provozierten ihren Rauswurf aus der Koalition. Seither fehlt Andrus Ansips Regierung eine Stimme zur Mehrheit. ${ }^{4}$

\section{Lettland}

\subsection{Parteiensystem}

Das Parteiensystem Lettlands ist weiterhin weniger orientiert an der Vertretung von sozioökonomischen Interessen der Wählerschaft als ethnisch segregiert, wobei russophile Parteien als links, lettische Parteien als rechts gelten. Es gibt hingegen keine erfolgreiche sozialdemokratische Partei. Trotz weiterer Umgruppierungen blieben die Blöcke bestehen.

„Lettlands Erste Partei“ (Latvijas Pirmā Partija) ging 2006 eine Listenkoalition mit der früher einmal sehr starken Partei „Lettlands Weg“ (Latvijas Ceľ̦̌) ein. Für beide Partner war diese Kooperation wichtig, um den Sprung ins Parlament zu schaffen. Während Lettlands Erste Partei an der Fünfprozenthürde zu scheitern drohte, war Lettlands Weg bereits eine Wahlperiode nicht mehr im Parlament vertreten. Andere potentielle Bündnispartner unter den liberal-konservativen, also lettisch orientierten politischen Kräften waren für beide Parteien nicht in Sicht. Die „Volkspartei“ (Tautas Partija) wie auch die „Neue Zeit“ (Jaunais Laiks) waren vor allem zu stark, um als ebenbürtiger Partner in Frage zu kommen. Die Neue Zeit war im Laufe der Wahlperiode wegen ihrer Anti-Korrruptionsrhetorik und dem damit verbundenen Scheitern der ersten Regierung unter Führung ihres Gründers, Einars Rep̌se, 2004 wie auch dem ähnlich gelagerten Austritt aus der Koalition 2006, nur ein halbes Jahr vor dem Urnengang, aus Sicht der beiden kleineren Kräfte auch keine verlässliche Alternative. Inhaltlich ist der Zusammenschluss von Erster Partei und Lettlands Weg eher eine überraschende Ehe, weil letztere immer eher eine liberale Partei auch im gesellschaftlichen Sinne war, während die Erste Partei, wegen der vielen aktiven Geistlichen auch als Priesterpartei bezeichnet, sich beispielsweise an die Spitze einer in der Bevölkerung verbreiteten Gegnerschaft gegen eine Homosexuellenparade gesetzt hatte. ${ }^{5}$

Die Listenkoalition aus „Bauernunion und Grünen“ (Zaḷo un Zemnieku Savienība) stellte den Bürgermeister der budgetstarken Hafenstadt Ventspils, Aivars Lembergs, als Spitzenkandidaten auf, obwohl bereits damals die Staatsanwaltschaft in verschiedenen Korrup-

4 Bei den Parlamentswahlen vom 6. März 2011 wurde die Mitte-Rechts-Regierung unter Ministerpräsident Andrus Ansip im Amt bestätigt. Auf diese Wahl kann hier nicht genauer eingegangen werden.

5 Vgl. Niels Dehmel / Axel Reetz, Extremismus in Lettland, in: Eckhard Jesse / Tom Thieme (Hrsg.), Extremismus in den EU-Staaten, Wiesbaden 2011, S. 213 - 228. 
tionsfällen gegen ihn ermittelte und nicht zuletzt deshalb kaum anzunehmen war, dass potentielle Koalitionspartner ihn als Regierungschef akzeptieren würden. Die Wähler wurden so im Grunde getäuscht, denn Lembergs kandidierte nicht einmal für ein Abgeordnetenmandat. Nachdem ein Verfahren bereits eröffnet war, wurde er im Frühjahr 2007 wegen Verdunklungsgefahr verhaftet und stand anschließend ungefähr ein Jahr unter Hausarrest.

Die neue Partei „Harmoniezentrum“ (Saskaņas Centrs) entstand 2005 durch neuerliche Umgruppierungen mehrer russophiler Parteien um die „Partei der Volksharmonie“, an die sich auch der neue Name anlehnt. Deren Gründer, Jänis Jurkäns, hatte sich allerdings schon vorher aus der aktiven Politik zurückgezogen. Sein Nachfolger, Jänis Urbanovičs, führte die Partei in diese neue Koalition, an der auch das „Neue Zentrum“ (Jaunais Centrs) des früheren stellvertretenden Bürgermeisters von Riga, Sergej Dolgopolov, beteiligt ist, das $2004 \mathrm{zu}$ den Kommunalwahlen des folgenden Jahres gegründet worden war. Der dritte Partner ist die „Daugavpilser Stadtpartei“ (Daugavpils Pilsētas Partija). Vorsitzender der neuen Partei ist Nil Uschakov.

Der Grund für die Unübersichtlichkeit dieses Lagers liegt im häufigen Wechsel der Fraktionsgemeinschaften und Listenkoalitionen. So waren alle russophilen Parteien 1998 unter dem Harmonienamen angetreten und umfassten sowohl die moderaten, aus der „Volksfront" hervorgegangenen Kräfte als auch die Interfrontisten und Gegner der Auflösung der Sowjetunion. Diese Zusammenarbeit blieb auch 2002 bestehen und firmierte damals als „Für die Rechte des Menschen in einem integrierten Lettland“ (PCTVL, Par Cilvēka Tiesībām Vienotā Latvijā). ${ }^{6}$ Diese Bezeichnung stammte von den Interfrontisten.

Die „Sozialistische Partei“ (Sociālistiskā Partija) von Alfrēds Rubiks, dem früheren Putschisten, der selbst auf Grund seiner Vergangenheit nicht kandidieren darf7, arbeitet nur noch mit der aus dem gleichen Lager hervorgegangenen „Gleichberechtigung“ (Līdztiesība) zusammen. Unter diesem Namen war ihre Liste auch 1993 noch separat zu den Wahlen angetreten. Sie ist mit Tatjana Schdanok bereits seit 2004 im Europäischen Parlament vertreten, wo sie sich der Fraktion der Grünen angeschlossen hat. ${ }^{8}$

Beide Parteien setzen sich für die Integration der russischsprachigen Bevölkerung ein, was auf Ablehnung der lettischen Parteien stößt, mit der Folge, dass die moderaten Kräfte bislang mit Ausnahme der Unterstützung der Minderheitsregierung Mãris Gailis zwischen 1994 und 1995 durch Anti-Koalitionen von der Macht ausgeschlossen worden sind. Dennoch handelt es sich auch bei den Nachfolgern der früheren Interfrontisten nicht um AntiSystem-Parteien ${ }^{9}$, die einen anderen Staat befürworten oder einen Anschluss an Russland.

6 In englischsprachigen Publikationen wird gerne der Begriff Menschenrechte verwendet, wie die Partei sich im russischen Original bezeichnet.

7 Stichtag für die Verweigerung des Rechtes auf passive Wahlteilnahme war der 13. Januar 1991, nachdem eine fortgesetzte Mitgliedschaft in der Kommunistischen Partei als Ausschlussgrund einer Kandidatur galt. An diesem Tag wurden in der litauischen Hauptstadt Vilnius Fernsehturm und Fernsehgebäude überfallen. Dabei kamen 13 Menschen ums Leben.

8 Für Schdanok gilt das Verbot der Kandidatur wie für Rubiks, die von Seiten der EU jedoch für die Wahlen zum EU-Parlament abgelehnt wurde.

9 Segert bezeichnete diese, die russische Minderheit vertretenden Parteien, einmal als Anti-SystemParteien. Vgl. Dieter Segert, Parteien und Parteiensysteme in der Konsolidierung der Demokratien Osteuropas, in: Wolfgang Merkel / Eberhard Sandschneider (Hrsg.), Systemwechsel 3: Parteien im Transformationsprozess, Opladen 1997, S. 57 - 100, S. 67. 
Allerdings ist ihre Einstellung zur NATO und EU teilweise kritisch, doch ein Austritt steht nicht auf der Agenda.

Das Harmoniezentrum, das sich seit der Trennung von den Sozialisten verändert hat, ist dezidiert europafreundlich, auf Marktwirtschaft orientiert und drängt mit diesem Schritt zur politischen Mitte. Jede Regierungskrise wird genutzt, um die eigene Regierungsfähigkeit zu demonstrieren. Die Partei hält unter Jānis Urbanovičs 13 der 17 Sitze der Fraktion in der Saeima. Urbanovičs suchte zunächst erfolglos die Nähe der Koalition aus Lettlands Erster Partei und Lettlands Weg. Der Politiker Dainis Turlais, der in den vergangenen Jahren schon in vielen eher linksgerichteten Parteien wirkte, war sogar von der Partei der Volksharmonie zum genannten potentiellen Partner gewechselt.

\subsection{Regierungen}

Obwohl die Neue Zeit der Sieger der Wahl von 2002 gewesen war, gelang es ihr nicht, in jener Wahlperiode führende Partei zu bleiben. Als Anti-Korruptionskraft angetreten, stieß sie unter den anderen Parteien des liberal-konservativen Lagers auf Ablehnung. Nach dem Sturz der von ihr geführten Regierung 2004 war dieses Lager, das im Parlament immerhin über eine Dreiviertelmehrheit verfügte, erst nach deutlichen Worten von Staatspräsidentin Vaira Vike-Freiberga in der Lage, eine Minderheitsregierung zu installieren. Aber der Machtkampf zwischen der Neuen Zeit und der Volkspartei dauerte an.

Diese stürzte schließlich im Herbst 2004 nach nur einem halben Jahr im Amt die von ihr selbst getragene Minderheitsregierung unter Indulis Emsis, indem die Fraktion dem Haushalt ihres eigenen Finanzministers nicht zustimmte, womit das Parlament nach der lettischen Verfassung automatisch dem Kabinett das Misstrauen ausspricht. Der Fraktionschef der Volkspartei, Aigars Kalvìtis, konnte nun selbst eine Regierung bilden, an der sich die Neue Zeit sogar beteiligte und damit in die Exekutive zurückkehrte.

Sie wurde anschließend aber von inneren Konflikten erschüttert, weil viele Politiker wie auch die Wählerschaft den Parteigründer Repšse für die Misserfolge der Partei verantwortlich machten. Der Exillette und Wirtschaftsminister im Kabinett Kalvìtis, Krišjānis Kariņ̌s, übernahm schließlich den Parteivorsitz. Wegen der fortgesetzten Bemühungen im Kampf gegen die Korruption kam er allerdings neuerlich in Konflikt mit der Volkspartei und verließ die Regierung im April 2006. Kalvītis führte bis zur Wahl im Oktober eine Minderheitsregierung bis zu den Wahlen ein halbes Jahr danach.

Dieses halbe Jahr stand ganz im Einruck des politisch wohl schwerwiegendsten Skandals in Lettland seit der Unabhängigkeit 1991, der in Anlehnung an Watergate von der Öffentlichkeit Jūrmalgeit genannt wurde. Nach den Kommunalwahlen 2005 versuchten führende Politiker eine Absprache zu erreichen, wer im Kurort Jūrmala, der auch als Rigas Strand bezeichnet wird, als Bürgermeister installiert werden sollte. Die Versuche des Stimmenkaufs wurden per Telefon getätigt, wobei die Gespräche aufgezeichnet worden waren und später publik wurden.

Das Ergebnis der Wahl vom 7. Oktober 2006 überraschte wenig; es bestätigte wie in Umfragen präzise prognostiziert die im Amt befindliche Minderheitsregierung und stattete sie mit einer parlamentarischen Mehrheit aus - eine Besonderheit in der unruhigen politischen Landschaft Lettlands. Der Koalition genügte die recht knappe Mehrheit von einem 


\begin{tabular}{|c|c|c|}
\hline Partei & $\begin{array}{l}\text { Stimmen } \\
\text { (in Prozent) }\end{array}$ & Mandate \\
\hline Volkspartei (Tautas Partija) & 19,56 & 23 \\
\hline Union von Grünen und Bauern (Zaḷo un Zemnieku Savienība) & 16,71 & 18 \\
\hline Neue Zeit (Jaunais Laiks) & 16,38 & 18 \\
\hline Harmoniezentrum (Saskaņas Centrs) & 14,42 & 17 \\
\hline $\begin{array}{l}\text { Wahlvereinigung von Lettlands Erster Partei (Latvijas Pirmā Partija) und } \\
\text { der Partei Lettlands Weg (Latvijas Cẹ̦šs) }\end{array}$ & 8,58 & 10 \\
\hline $\begin{array}{l}\text { Vereinigung „Für Vaterland und Freiheit“ / LNNK (Apvienība „Tēvzemei } \\
\text { un Brīvïbai“/ LNNK) }\end{array}$ & 6,94 & 8 \\
\hline $\begin{array}{l}\text { Politische Vereinigung von Organisationen „Für die Menschenrechte in } \\
\text { einem integrierten Lettland“ (Politisko organizāciju apvienība „Par } \\
\text { cilvēka tiesībām vienotā Latvijā") }\end{array}$ & 6,03 & 6 \\
\hline $\begin{array}{l}\text { Lettlands Sozialdemokratische Arbeiterpartei (Latvijas } \\
\text { Sociāldemokrātiskā Strādnieku Partija) }\end{array}$ & 3,50 & \\
\hline $\begin{array}{l}\text { Politische patriotische Vereinigung „HEIMAT“ (Politiskā patriotiskā } \\
\text { apvienība „DZIMTENE“) }\end{array}$ & 2,08 & \\
\hline Partei „Alles für Lettland!“ (Partija „Visu Latvijai!“) & 1,48 & \\
\hline „Neue Demokraten“(„Jaunie demokrāti“) & 1,27 & \\
\hline $\begin{array}{l}\text { Politische Organisation „PENSIONÄR- UND RENTNERPARTEI“ } \\
\text { (Politiskā organizācija „PENSIONĀRU UN SENIORU PARTIJA“) }\end{array}$ & 0,79 & \\
\hline $\begin{array}{l}\text { Politische Organisation (Partei) „Die Euroskeptischen“ } \\
\text { (Politiskā organizācija (partija) „Eiroskeptik̦i“) }\end{array}$ & 0,37 & \\
\hline Mara Land (Māras Zeme) & 0,48 & \\
\hline Partei „Unser Land“ (Partija „Mūsu Zeme“) & 0,23 & \\
\hline Partei der sozialen Gerechtigkeit (Sociālā Taisnīguma Partija) & 0,17 & \\
\hline Union der nationalen Kräfte (Nacionālā Spēka Savienība) & 0,13 & \\
\hline $\begin{array}{l}\text { „LETTISCHES LETTLAND“ nationalpolitische Organisation der letti- } \\
\text { schen Verteidigung („LATVIEŠU LATVIJA“ nacionālpolitiska Latviešu } \\
\text { Aizstāvības Organizācija) }\end{array}$ & 0,12 & \\
\hline Partei „Vaterlandsunion“ (Partija „Tēvzemes savienība“) & 0,12 & \\
\hline
\end{tabular}

Mandat jedoch nicht, und so wurde „Für Vaterland und Freiheit/LNNK“10 (Tēvzemei un Brīivibai/LNNK) als vierter Partner gewonnen.

Kleinere Überraschungen gab es nur Personen betreffend, so wurden Parlamentspräsidentin Ingrīda Üdre von der Union von Bauern und Grünen und ihr Stellvertreter Jänis Straume von TB/LNNK nicht wieder ins Parlament gewählt, weil die Wähler sie auf den lose gebundenen Listen zu oft ausgestrichen hatten. Eigentlich sollte Udre im Amt verbleiben, wurde angesichts des Ergebnisses von ihrer Partei dann aber durch den früheren Ministerpräsidenten Indulis Emsis ersetzt, der seinerseits im Herbst 2007 zurücktreten musste,

10 LNNK ist die alte Abkürzung der nationalen Unabhängigkeitsbewegung (Latvijas Nacionālā Neatkarības Kustïba), die sich schon vor vielen Jahren mit „Für Vaterland und Freiheit“ vereinigt hatte. 
weil die Staatsanwaltschaft gegen ihn ein Ermittlungsverfahren wegen bewusster Falschaussage in einem mit der Hafenstadt Ventspils verknüpften Prozess eingeleitet hatte. In Äußerungen gegenüber der Öffentlichkeit räumte Emsis sein Fehlverhalten faktisch ein. Auch der frühere Ministerpräsident und Zentralbankchef Einars Rep̌š wurde von vielen Wählern seiner Partei gestrichen, doch die gleichzeitige noch höhere Zahl von Plus-Zeichen sicherte ihm das Mandat.

Die eindrucksvolle Bestätigung der Regierung Kalvītis war jedoch weniger ein Zeugnis der Zustimmung der Wähler zu diesen politischen Kräften als vielmehr Mangel an Alternativen. Die wesentlichen an der Macht befindlichen und oligarchisch strukturierten Parteien wurden nach diesem Erfolg jedoch übermütig, und so entwickelte sich die neue Wahlperiode - ganz im Gegensatz zu dem in Lettland seit der Unabhängigkeit einmalig stabilen Wahlergebnis - in kürzester Zeit zur bislang stürmischsten.

Faktisch unmittelbar nach der Wahl zum Jahreswechsel 2006/2007 versuchte die Regierung unter Führung der Volkspartei, Veränderungen im Gesetz über die nationale Sicherheit durchzusetzen. Dabei wurde Artikel 81 der Verfassung angewandt, demgemäß ein eiliges Gesetz außerhalb der Sitzungsperiode durch die Regierung verabschiedet werden kann. Präsidentin Vaira Vike-Freiberga wies nach Artikel 71 das Gesetz zur neuerlichen Debatte an das Parlament zurück, das das Dokument jedoch neuerlich bestätigte. Anschließend verweigerte sie nach Artikel 72 die Ausfertigung. Der in dieser Norm mögliche Aufschub um zwei Monate ist vorgesehen, der Bevölkerung Zeit zur Initiierung eines Referendums zu geben, wofür es der Unterschriften eines Zehntels der Wahlberechtigten bedarf, also derzeit etwa 150.000. Diese Summe wurde mit mehr als 200.000 Unterschriften deutlich überschritten. Daraufhin nahm die Regierung die Novelle zurück, und der umstrittene Verfassungsartikel 81 wurde in aller Eile einer Empfehlung des früheren Präsidenten des Verfassungsgerichtes folgend vom Parlament gestrichen. ${ }^{11}$ Bereits 2008 gab es aus den Reihen von Regierung und Parlament die ersten Meinungsäußerungen, der Schritt sei übereilt gewesen und der betreffende Artikel sollte wieder in Kraft gesetzt werden.

Die Zentrale Wahlkommission legte im Rahmen der gesetzlich vorgesehenen Fristen den 7. Juli 2007 als Datum für das Referendum über die Novelle des Gesetzes über die nationale Sicherheit fest, ein Samstag, wie es das Gesetz in Lettland für einen Wahltag verlangt. Den „07.07.07“ hatten jedoch zahlreiche Paare als Hochzeitstag gewählt. Das erforderliche Quorum, das bei der Hälfte der Beteiligung an den vorangegangenen Parlamentswahlen liegt, wurde vermutlich auch deshalb nicht erreicht. Wegen der vorherigen Annullierung des betreffenden Gesetzes hatte die Abstimmung allerdings nur noch symbolischen Charakter. Dennoch begann mit dem Referendum in Lettland eine Zeit der politischen Aktivität der Bevölkerung, wie es sie seit den Massendemonstrationen während des Zusammenbruchs der Sowjetunion nicht mehr gegeben hatte.

Dieser Eingriff in das politische Tagesgeschehen war die letzte bedeutende Amtshandlung von Präsidentin Vaira Vike-Freiberga, deren zweite Amtszeit 2007 endete, so dass das Parlament bereits kurz vor dem Tag der Abstimmung einen Nachfolger wählen musste. Der in der Bevölkerung populäre frühere Präsident des Verfassungsgerichtes, Aivars Endziņš, wurde vom oppositionellen Harmoniezentrum unterstützt. Nach den Schritten der Amtsinhaberin war jedoch zu vermuten, dass die Regierung einen genehmeren Kandidaten

11 Der Artikel verdankt seine Existenz dem Umstand, dass die Verfassungsväter 1922 dem Nachholbedarf der Gesetzgebung in einem neu gegründeten Staat Rechnung tragen wollten. 
suchen würde, der mit dem Arzt Valdis Zatlers dann auch gefunden wurde. ${ }^{12}$ Seine Wahl war unproblematisch, weil das Parlament in Lettland den Präsidenten mit absoluter Mehrheit wählt. ${ }^{13}$ Zatlers geriet kurz nach der Wahl bereits in moralische Erklärungsnot, als er zugeben musste, von Patienten - was in Lettland gang und gäbe ist - Dankesgeschenke angenommen hatte, ohne diese zu versteuern. In den folgenden Monaten fiel er durch Unbeholfenheit auf. ${ }^{14}$

In diesen Monaten wurde die Öffentlichkeit außerdem erschüttert, weil sich mit der Politik nur mittelbar verbundene, zweifelhafte Ereignisse häuften. Im September gelangte der frühere Mitarbeiter des Sicherheitsdienstes von Parlament und Präsident, Edgars Gulbis, der wegen des Verdachts des Betrugs unter Verwendung gefälschter Dokumente verhaftet worden war, während einer Überführung im September auf einer Brücke über die Dauga$\mathrm{va}^{15}$, deren Fahrbahn sich etwa 20 Meter über der Wasseroberfläche befindet, angeblich mit Handschellen gefesselt, aus dem fahrenden Streifenwagen in den Fluss. Während Gulbis dies als Anschlag bezeichnete und behauptete, er sei gestoßen worden, sprach die Polizei von einem Fluchtversuch. Dem Streifenwagen war der Privatwagen von Gulbis' Lebensgefährtin gefolgt.

Im Herbst 2007 wollte die Regierung Kalvitis den Leiter der Anti-Korruptionsbehör$\mathrm{de}^{16}$, Andrej Loskutov, wegen unkorrekter Amtsführung entlassen. Diese Behörde war nach der Verabschiedung eines Gesetzes zur Verhinderung von Korruption 1995 - auch vor dem Hintergrund der Lettland regelmäßig ausgestellten schlechten Noten bei Untersuchungen verschiedener internationaler Organisationen - im Jahre 2002 eingerichtet worden. Der Wunsch der Regierung brachte jedoch das Fass zum Überlaufen: 5.000 Menschen demonstrierten am 18. Oktober, dem Tag der dann vertagten Entscheidung vor dem Parlament, wo noch zahlreiche Minister ihre Unterstützung von Kalvitis' Entscheidung rechtfertigten. Am 3. November wurde in der Altstadt von Riga die größte Kundgebung seit den Demonstrationen der Gorbatschow-Zeit organisiert, die im Volksmund die Bezeichnung „Regenschirmrevolution “ (lietussargu revolūcija) erhielt, weil auf dem Domplatz an diesem regnerischen Tag ein Meer von Schirmen zu sehen war. Bei beiden Gelegenheiten skandierten die Demonstranten: „Löst das Parlament auf“. Dies kann der Präsident nach Artikel 74 der Verfassung veranlassen, worüber dann ein Referendum stattfinden muss, das im Falle eines ablehnenden Entscheides ihn selbst das Amt kostet. Loskutovs wurde schließlich 2007 zwar nicht entlassen, jedoch wegen Unstimmigkeiten in der Buchhaltung seiner Behörde im Jahr darauf.

12 Da die Koalitionsparteien bis kurz vor der Abstimmung die Identität ihres Kandidaten geheimgehalten hatten, verbreitete sich das Gerücht, Zatlers sei bei einem privaten Treffen der Koalitionsspitzen im Rigaer Zoo auserwählt worden.

13 Nach der erfolgreichen Bestellung der Regierungskandidaten sorgte ein Abgeordneter der größten Regierungspartei, der Partei des Ministerpräsidenten Jānis Lagzdiňš, am Fenster des Abgeordnetenhauses für weitere Aufregung, wo er den ausgestreckten linken Arm mit Faust und die andere Hand in den Ellebogen legend zeigte. Es fehlte nur der ausgestreckte Mittelfinger. Angeblich habe er sich an einen konkreten Bekannten vor dem Gebäude wenden wollen, was angesichts der dort versammelten Anhänger Endzinšs’ wenig überzeugend klang.

14 Ein Zitat wurde schnell populär: „Wer bin ich?“. In Lettland gab es die verbreitete Meinung, dem Präsidenten fehlten als Orthopäden die Kenntnisse des Politischen.

15 Dieser Fluss ist in Riga etwa ein halben Kilometer breit.

$16 \mathrm{KNAB}$ - Korupcijas novēršanas un apkārošanas birojs (Büro zur Verhinderung und Bekämpfung von Korruption). 
Die politische Elite des Landes hatte nun endgültig die öffentliche Meinung grundlegend gegen sich. Dies betraf den Ministerpräsidenten und damit seine Volkspartei, deren Geschlossenheit nun Risse aufwies. Der Minister für Regionalpolitik, Aigars Štokenbergs, wurde wegen angeblicher Bemühungen um eine eigene Parteigründung in Abwesenheit trotz seiner Funktion als Präsidiumsmitglied aus der Partei ausgeschlossen. Parteifreund und Außenminister Artis Pabriks trat daraufhin zurück. Sie erneuerten ihr Parlamentsmandat und gründeten mit weiteren, außerhalb des politischen Alltags stehenden Personen die Gesellschaft für eine andere Politik (Sabiedrība Citai Politikai).

Bald darauf spaltete sich von der Neuen Zeit unter der früheren Außenministerin und Übergangs-EU-Kommissarin, Sandra Kalniete, die Bürgerliche Union (Pilsoniskā Savienība) ab, der sich auch der EP-Abgeordnete Girts Kristovskis von der konservativen Für Vaterland und Freiheit anschloss. Der Grund für diesen Schritt war die Uneinigkeit über eine neuerliche Regierungsbeteiligung, während Kristovskis seine Partei aus Wut über den verlorenen Kampf um den Vorsitz gegen MdEP Roberts Zïle verließ. Diese neue Partei war dank weiterer Übertritte sofort stark genug, um eine eigene Fraktion im Parlament zu bilden.

Die Frage einer neuerlichen Regierungsbeteiligung war virulent geworden, weil der Druck der Öffentlichkeit auf Veränderungen in der Politik groß war. Faktisch forderte eine außerparlamentarische Opposition den Rücktritt der amtierenden Regierung Aigars Kalvitis, die im Parlament aber über eine Mehrheit verfügte und deren Partner gleichzeitig auf eigene Veranlassung das Bündnis eigentlich nicht verändern wollten. Auch gab es zur regierenden Koalition ohne Beteiligung der Neuen Zeit mit oder ohne Ausscheiden eines aktuellen Bündnispartners keine politische Alternative. Aus der Erfahrung der Vergangenheit wollte der größere Teil der Neuen Zeit sich für die als korrupt betrachteten politischen Gegner nicht wieder als Mehrheitsbeschaffer missbrauchen lassen, während einige Abgeordnete der Überzeugung waren, man könne in der Regierung mehr bewegen als in der Opposition.

Kalvìtis kündigte schließlich seinen Rücktritt für den 5. Dezember 2009 an, den dritten Jahrestag seines Amtsantrittes. Sein Nachfolger wurde ohne eine Änderung der Zusammensetzung des Regierungsbündnisses Ivars Godmanis, der das Land auch in die Unabhängigkeit geführt hatte. Kaum war er im Amt, wurde Lettland von der Finanzkrise stark getroffen; zum 1. Januar 2009 wurde kurzerhand etwa die Umsatzsteuer um drei Prozent erhöht. In den Medien verlor sich Godmanis bei Erklärungsversuchen des Regierungshandelns in Zahlen und Details, was seine Ausführungen nahezu unverständlich machte. Wenig verwunderlich, dass einfache Menschen in Anlehnung an die ökonomisch schwierige Zeit unter der Volksfrontregierung Anfang der 1990er Jahre urteilten, dass es immer, wenn Godmanis an der Macht sei, eine Krise gebe. Ende 2008 wurde handstreichartig die einzige Bank mit Hauptsitz in Lettland, die Parex-Bank, vom Staat übernommen. Am 13. Januar 2009 rief schließlich die neue Partei „Gesellschaft für eine andere Politik“ zur Demonstration auf. Diese endete in Straßenschlachten, was das Eingreifen des Präsidenten provozierte. Er verlangte neue Gesichter in der Regierung, womit er de facto Godmanis zum Rücktritt zwang. Neuer Regierungschef wurde der erst 37-jährige Valdis Dombrovskis, MdEP von der Neuen Zeit.

Anschließend stellte Präsident Zatlers Parlament und Regierung ein Ultimatum bis zum 31. März. Bis dahin sollten konkrete politische und gesetzgeberische Schritte vollzogen werden. Im April rief Zatlers eine außerordentliche Kabinettssitzung hinter verschlossenen Tü- 
ren zusammen, der eine weitere im September folgte, die live im Fernsehen übertragen wurde. Nachdem das kritische Moment der Verabschiedung des Haushaltes für 2010 überstanden war, wagte sich Rigas Vize-Bürgermeister Ainārs Šlesers mit Vorschlägen vor, wann und warum die Regierung gestürzt werden müsse. Dieser Schritt ist gewiss im Zusammenhang mit der Rückkehr von Andris Šķēle in die Politik zu sehen. Der frühere dreimalige Regierungschef, der über Jahre nur das „einfache Mitglied“ seiner Partei war, galt als letzte Hoffnung für die Wahl am 2. Oktober 2010. ${ }^{17}$ Parteivorsitzender Mareks Seglinš räumte den Vorsitz mit der Begründung, dies seien keine Zeiten für Juristen, sondern für Ökonomen. ${ }^{18}$

\section{Litauen}

\subsection{Parteiensystem}

Erst kurz vor der Wahl vom Oktober 2008 hatte der Fernsehentertainer Arūnas Valinskas mit einigen im Rampenlicht stehenden Persönlichkeiten die Partei der „Nationalen Wiedergeburt“ (Tautos prisikèlimo partija) gegründet, die den Wunsch der Wähler nach etwas anderem befriedigte, was den Erfolg der Populisten, insbesondere der Partei „Ordnung und Gerechtigkeit“ (Partija Tvarka ir teisingumas), geführt vom früheren Staatspräsidenten Rolands Paksas, beschränkte. Darüber hinaus bewog der Vorsitzende der Vaterlandsunion, Andrius Kubilius, die bereits in der politischen Bedeutungslosigkeit fast verschwundenen Christdemokraten zu Jahresbeginn 2009 dazu, sich zu vereinigen. Diese waren seit 2000 nur noch mit zwei Direktmandaten im Parlament vertreten gewesen und hatten diese 2004 auch noch verloren. ${ }^{19}$

\subsection{Regierungen}

Wegen des großen Erfolgs der Arbeitspartei und ihres unter Korruptionsverdacht stehenden Vorsitzenden Viktor Uspaskich war es zunächst zu einer Koalition dieser populistischen Partei mit den Sozialdemokraten unter Führung des Wahlverlierers Algirdas Brazauskas gekommen. Als auch gegen ihn zahlreiche Korruptionsvorwürfe erhoben wurden, trat Brazauskas im Mai 2006 zurück, nachdem die Arbeitspartei aus der Koalition ausgeschieden war. Zuvor bereits war deren Vorsitzender von einem Aufenthalt in seiner Heimat Russland nicht wieder nach Litauen zurückgekehrt.

Anschließend suchte die politische Elite nach einem Kompromisskandidaten, der wenigstens eine Duldung erreichen könnte, um die Arbeitspartei von der Macht fernzuhalten.

17 Bei der Parlamentswahl 2010 haben die Letten die Mitte-Rechts-Regierung von Ministerpräsident Valdis Dombrovskis im Amt bestätigt. Auf diese Wahl kann hier nicht genauer eingegangen werden.

18 Details zu den innenpolitischen Ereignissen in Lettland von Ende 2007 bis 2010 werden kommentiert auf dem Blog des Autors. Vgl. http://axelreetz.blogspot.com (Abruf am 17. Januar 2010).

19 Vgl. Andreas Michael Klein, Litauen hat gewählt. Zusammenfassung der ersten Runde der Parlamentswahl, in: Konrad Adenauer Stiftung (Hrsg.), Länderbericht Litauen, Oktober 2008. 


\begin{tabular}{|c|c|c|c|c|}
\hline Partei & Prozent & Mandate & $\begin{array}{l}\text { Direkt- } \\
\text { mandate }\end{array}$ & Gesamt \\
\hline $\begin{array}{l}\text { Vaterlandsunion - Litauens Christdemokraten } \\
\text { (Tèvynės sąjunga - Lietuvos krikščionys demokratai) }\end{array}$ & 19,72 & 18 & 27 & 45 \\
\hline $\begin{array}{l}\text { Litauens Sozialdemokratische Partei (Lietuvos } \\
\text { socialdemokratų partija) }\end{array}$ & 11,72 & 10 & 15 & 25 \\
\hline $\begin{array}{l}\text { Partei der Nationalen Wiedergeburt (Tautos } \\
\text { prisikèlimo partija) }\end{array}$ & 15,90 & 13 & 3 & 16 \\
\hline $\begin{array}{l}\text { Partei Ordnung und Gerechtigkeit (Partija Tvarka ir } \\
\text { teisingumas) }\end{array}$ & 12,86 & 11 & 4 & 15 \\
\hline $\begin{array}{l}\text { Liberale Bewegung der Republik Litauen (Lietuvos } \\
\text { Respublikos liberalų sąūidis) }\end{array}$ & 5,73 & 5 & 6 & 11 \\
\hline $\begin{array}{l}\text { Koalition Arbeitspartei + Jugend (Koalicija Darbo } \\
\text { partija + jaunimas) }\end{array}$ & 8,99 & 8 & 2 & 10 \\
\hline $\begin{array}{l}\text { Union von Liberalen und Zentrum (Liberalų ir cen- } \\
\text { tro sąjunga) }\end{array}$ & 5,34 & 5 & 3 & 8 \\
\hline $\begin{array}{l}\text { Litauens Wahlaktion der Polen (Lietuvos Lenkų } \\
\text { Rinkimų Akcija) }\end{array}$ & 4,79 & & 3 & 3 \\
\hline $\begin{array}{l}\text { Bewegung des Bauernvolkes Litauens (Lietuvos } \\
\text { valstiečių liaudininkų sąjunga) }\end{array}$ & 3,73 & & 3 & 3 \\
\hline $\begin{array}{l}\text { Neue Union (Sozialliberale) (Naujoji sąunga (soci- } \\
\text { alliberalai)) }\end{array}$ & 3,64 & & 1 & 1 \\
\hline Partei „Frontas“(„Fronto“ partija) & 3,24 & & & \\
\hline Partei „Junges Litauen“ (Partija „Jaunoji Lietuva“) & 1,75 & & & \\
\hline $\begin{array}{l}\text { Partei der zivilen Demokratie (Pilietinès demokrati- } \\
\text { jos partija) }\end{array}$ & 1,11 & & & \\
\hline $\begin{array}{l}\text { Bewegung der Russen in Litauen (Lietuvos rusu } \\
\text { sajunga) }\end{array}$ & 0,92 & & & \\
\hline $\begin{array}{l}\text { Litauens Sozialdemokratische Bewegung (Lietuvos } \\
\text { socialdemokratų sąunga) }\end{array}$ & 0,86 & & & \\
\hline Litauens Zentrumspartei (Lietuvos centro partija) & 0,70 & & & \\
\hline Einzelkandidaten & & & 4 & 4 \\
\hline \multicolumn{5}{|c|}{$\begin{array}{l}\text { Quelle: http://www.vrk.lt/en/news-and-information/preliminary-results-of--election-to-the-seimas- } \\
\text { 2008-after-the-second-poll--.html (Abruf am 17. Januar 2011); http://www.vrk.lt/2008_seimo_rinki- } \\
\text { mai/output_lt/rezultatai_daugiamand_apygardose/rezultatai_daugiamand_apygardose1 turas.html (Ab- } \\
\text { ruf am 17. Januar 2011). }\end{array}$} \\
\hline
\end{tabular}

Dieser Prozess war langwierig und schwierig, weil die einzige Möglichkeit in einer Kooperation zwischen den beiden Hauptkontrahenten des litauischen Parteiensystems, den postkommunistischen Sozialdemokraten und der aus dem Widerstand hervorgegangenen Heimatunion, bestand. Im Juli wurde das Kabinett einer sozialdemokratischen Minderheitsregierung unter Gediminas Kirkilas bestätigt. Die Heimatunion enthielt sich der Stimme. Der Regierung gehörten neben den Sozialdemokraten die Bauernunion, die Liberale und Zentrumsunion sowie die von der Arbeitspartei abgespaltenen Bürgerlichen Demokraten an. 


\subsection{Regierungsbildung}

Die Regierungsbildung erfolgte zügig. Bereits unmittelbar nach der Wahl einigten sich die siegreiche Heimatunion, die Liberale Bewegung und die Liberale und Zentrumsunion mit der Entertainerpartei auf eine Koalition unter Andrius Kubilius, der sich zwei weitere unabhängige Abgeordnete anschließen wollen. Dieses Tempo hatte das deutliche Wählervotum zugunsten einer konservativen Politik ermöglicht wie auch der klare Vorsprung der Heimatunion. Die Partei der Arbeit von Viktor Uspaskich ihrerseits erklärte, sie werde, wenn auch nicht Teil der neuen Koalition, im Parlament nicht gegen sie stimmen.

Gleichzeitig mit der Parlamentswahl fand ein Referendum über die Verlängerung der Laufzeit des Kernkraftwerkes Ignalina im Osten des Landes statt. Im Rahmen der Betrittsverhandlungen mit der Europäischen Union hatte sich das Land verpflichtet, die den Reaktoren in Tschernobyl gleichenden Blöcke bis spätestens 2009 abzuschalten. Angesichts knapper Energieressourcen in den baltischen Staaten und der damit verbundenen Abhängigkeit von Russland suggerierte die litauische Regierung der Bevölkerung, dass sich an diesem Beschluss rütteln ließe. Die Bedeutung des Kraftwerkes als Arbeitgeber wurde auch dadurch deutlich, dass die Ablehnung dieser Energieproduktion gerade in der näheren Umgebung von Ignalina besonders gering war. Insgesamt votierten von den abgegebenen Stimmen 91,4 Prozent für die Laufzeitverlängerung, 8,6 Prozent dagegen. ${ }^{20}$

Der Fernsehentertainer Arūnas Valinskas wurde Parlamentspräsident. Doch später wurden Vorwürfe gegen ihn und seine Frau erhoben, das Ehepaar unterhalte Kontakte zum organisierten Verbrechen in der zweitgrößten Stadt des Landes, Kaunas. Valinskas bestritt dies und folgte der Empfehlung der neuen Präsidentin zum Rücktritt nicht. Im September 2009 wurde er schließlich mit 95 von 141 Stimmen durch das Parlament abgewählt. Dieser Vorgang bedrohte die Regierung von Ministerpräsident Kubilius mittelbar, weil die Partei Valinskas' Koalitionspartner ist. Da sich die Partei der Nationalen Wiedergeburt außerdem gespalten hat, verlor das Kabinett an Rückhalt.

\subsection{Präsidentschaftswahl}

Im Jahre 2009 lief die zweite Amtszeit von Staatspräsident Valdas Adamkus ab. Die Wahl eines Nachfolgers verlief unspektakulär, obwohl es zahlreiche Kandidaten gab, denn die Kandidatur der EU-Kommissarin für Haushalt und Finanzen, Dalia Grybauskaite, galt lange vor dem Urnengang - in Litauen wird das Präsidentenamt durch Direktwahlen besetzt - als in der Bevölkerung erwünscht und erwartet. Grybauskaité wurde schließlich mit überzeugender Mehrheit bereits im ersten Wahlgang gewählt, allerdings beteiligten sich nur 51,7 Prozent der Wahlberechtigten.

Dalia Grybauskaite arbeitete als promovierte Ökonomin bereits Anfang der 1990er Jahre im Außenhandels- und Außenministerium und anschließend in den Vertretungen Litauens bei der EU und in Washington. Zwischen 1999 und 2001 wirkte sie im ersten Kabinett von Andrius Kubilius und wurde unter dem sozialdemokratischen Regierungschef Algirdas

20 Vgl. http://www.vrk.lt/2008_seimo_rinkimai/output_lt/referendumas/referendumas.html (Abruf am 17. Januar 2010). 


\begin{tabular}{|l|l|c|}
\hline \multicolumn{2}{|l|}{ Tabelle 4: Das Ergebnis der Wabl zum Staatspräsidenten am 22. Mai 2009 } \\
\hline Kandidat & \multicolumn{1}{|c|}{ Partei } & Prozent \\
\hline Dalia Grybauskaite & parteilos & 68,17 \\
Algirdas Butkevičius & Sozialdemokraten & 11,70 \\
Valentinas Mazuronis & Liberaldemokraten & 6,09 \\
Valdemar Tomaševski & Litauens Wahlaktion der Polen & 4,69 \\
Kazimira Prunskiene ${ }^{*}$ & Bauernpartei & 3,86 \\
Loreta Graužiniené & Arbeitspartei & 3,57 \\
Česlovas Jezerskas** & parteilos & 0,66 \\
\hline * Prunskiené war in der Umbruchszeit Ministerpräsidentin. \\
** General der Reserve. \\
Quelle: http://www.vrk.lt/2009_prezidento_rinkimai/output_lt/rezultatai_vienmand_apygardose/rezul- \\
tatai_vienmand_apygardose1turas.html (Abruf am 17. Januar 2011). \\
\hline
\end{tabular}

Brazauskas Finanzministerin, bis sie als EU-Kommissarin nach Brüssel kam. Ihre Arbeit brachte ihr 2005 den Titel der EU-Kommissarin des Jahres ein.

\section{Die baltischen Staaten als neue Mitglieder der Europäischen Union}

Estland, Lettland und Litauen sind nunmehr seit fünf Jahren Mitglied der Europäischen Union. Das bringt in der Bevölkerung tatsächliche und gefühlte Einstellungen mit sich. Wenig verwunderlich ist eine weit verbreitete Meinung, Brüssel regelte zu viel. Damit sind die Balten in Europa nicht allein. Aber es gab seit 2004 neue Möglichkeiten, die tatsächlich für die baltischen Länder gleichermaßen Vor- und Nachteile hatten. Zahlreiche Menschen siedelten um in jene Staaten, die ihre Arbeitsmärkte für die Neumitglieder sofort öffneten wie Irland und Großbritannien. Damit kam es vor Ort zu Engpässen bei den Arbeitskräften. Die Folge waren sehr schnell steigende Löhne. Da gleichzeitig Geschäftsbanken insbesondere aus Skandinavien umfangreich Kredite vergaben, kam es zu einem Boom auf dem Immobilienmarkt und in der Baubranche. Da viele dieser Kredite in Fremdwährung aufgenommen wurden, das Wirtschaftswachstum aber nicht im produzierenden Sektor, sondern in der Dienstleistungsbranche und eben auf dem Immobilienmarkt erwirtschaftet wurde, gerieten die nationalen Währungen im Rahmen der Finanzkrise unter Druck. Dies gilt insbesondere für Lettland, dessen Regierungen nach dem EU-Beitritt keine Rücklagen bildeten, sondern Steuergeschenke vergaben.

4.1. Die Wahlen zum Europäischen Parlament im Juni 2009 in Estland, Lettland und Litauen

Vor dem Hintergrund offensichtlicher Verbesserungen und Vorteile der EU-Mitgliedschaft wie auch einer nur von einem Teil der Gesellschaft verstandenen schwierigen wirtschaftlichen Situation fanden im Frühjahr 2009 die zweiten Wahlen zum EP seit dem Beitritt statt. 


\begin{tabular}{|l|c|c|l|}
\hline Tabelle 5: Die Wabl zum EP 2009 in Estland \\
\hline Partei & $\begin{array}{c}\text { Stimmen } \\
\text { (in Prozent) }\end{array}$ & Mandate & EP Fraktion \\
\hline Zentrumspartei & 26,07 & 2 & ALDE \\
Indrek Tarand (unabhängig) & 25,81 & 1 & GREENS/EFA \\
Reformpartei & 15,34 & 1 & ALDE \\
Vaterlandsunion und Res Publica & 12,21 & 1 & EPP \\
Sozialdemokraten & 8,70 & 1 & S\&D \\
\hline Quelle: http://www.vvk.ee/varasemad/?v=ep09 (Abruf am 17. Januar 2011). \\
\hline
\end{tabular}

\section{Estland}

In vielen Ländern der Europäischen Union ist die Beteiligung an der EP-Wahl aus verschiedenen Gründen gering. Auch in Estland betrug sie nur etwa 43 Prozent. Bemerkenswert ist jedoch die deutliche Steigerung im Vergleich zu nur 26 Prozent 2004.

Die kurz zuvor aus der Koalition geworfenen Sozialdemokraten konnten nicht profitieren und senden nur ihren bisherigen Finanzminister Ivari Padar nach Brüssel. Eine Überraschung war der Sohn des ehemaligen Ministerpräsidenten und ebenfalls Sozialdemokraten Indrek Tarand. Dieser Politiker diente früher unter dem konservativen Ministerpräsidenten Mart Laar in der Regierung. Das Außenministerium verließ er im Streit mit der Reformpartei-Vertreterin Kristiina Ojuland. Der seither als freier Journalist arbeitende Tarand erlangte durch seine Arbeit als Showmaster im estnischen Fernsehen Beliebtheit und erhielt als unabhängiger Kandidat mit 102.509 Stimmen und 25,8 Prozent fast so viele Stimmen wie die Zentrumspartei mit 103.525 und die Reformpartei mit 109.388. Letztere schickt allerdings mit Kristiina Ojuland ihre ehemalige Außenministerin nach Brüssel. Der nationalkonservative Tunne Kelam bleibt dem Parlament erhalten.

Lettland

Auch Lettland wird im EP mit politischen Schwergewichten vertreten sein. Neben der früheren EU-Interimskommissarin, Außenministerin und Mitbegründerin der Bürgerlichen

\begin{tabular}{|l|c|c|l|}
\hline Tabelle 6: Die Wabl zum EP 2009 in Lettland \\
\hline Partei & $\begin{array}{c}\text { Stimmen } \\
\text { (in Prozent) }\end{array}$ & Mandate & EP Fraktion \\
\hline Bürgerliche Union & 24,32 & 2 & EPP \\
Harmoniezentrum & 19,57 & 2 & S\&D / GUE / NGL \\
Für Menschenrechte in einem integrierten & 9,66 & 1 & GREENS / EFA \\
Lettland & 7,49 & 1 & ALDE \\
Lettlands Weg / Lettlands Erste Partei & 7,45 & 1 & ECR \\
Für Vaterland und Freiheit & 6,66 & 1 & EPP \\
Neue Zeit & \multicolumn{4}{|l}{ Quelle: http://www.cvk.lv/cgi-bin/wdbcgiw/base/eiro9.veles9_rezult.sak (Abruf am 17. Januar 2011). } \\
\hline
\end{tabular}


Union Sandra Kalniete entsendet ihre frühere Partei, die Neue Zeit, den Exil-Letten Krišjānis Karinš, der als Wirtschaftsminister das Kabinett Kalvitis aus Protest verlassen hatte und dessen Parteiführerschaft ebenfalls erfolglos geblieben war. Die früheren Interfrontisten, die in Lettland nicht für öffentliche Ämter kandidieren können, gehen gestärkt aus der Wahl hervor und schicken nun neben Tatjana Schdanok auch den ehemaligen Putschisten Alfrëds Rubiks nach Brüssel. Bezeichnenderweise kandidierten beide Politiker nicht auf derselben Liste und sitzen auch nicht in derselben Fraktion. Schdanok entschied sich für die Grünen, Rubiks für die Linke. Hingegen kann die nationalkonservative Für Vaterland und Freiheit/LNNK mit der Erneuerung des Mandats von Roberts Zïle nur noch einen Vertreter stellen. Vor fünf Jahren war der Erfolg dieser Partei mit vier Sitzen das Resultat eines Protestvotums. Zu diesen Großen der lettischen Politik seit der Unabhängigkeit gesellt sich der von Präsident Valdis Zatlers Anfang des Jahres zum Rücktritt gedrängte zweimalige Ministerpräsident Ivars Godmanis.

\section{Litauen}

Die EP-Wahl nur wenige Monate nach Amtsantritt der neuen Regierung stellte keinen Denkzettel für Ministerpräsident Kubilius dar. Aber ganz im Gegensatz zu Estland entwickelte sich die EU-Begeisterung in die Gegenrichtung, die Wahlbeteiligung sank von über 48 auf nur noch 21 Prozent - eine interessante Entwicklung auch angesichts des Umstandes, dass noch 2003 die Zustimmung zum Beitritt im Referendum in Litauen besonders hoch, in Estland hingegen mäßig gewesen war. Auch Litauen schickt politische Schwergewichte nach Brüssel wie etwa Vytautas Landsbergis, den Parlamentspräsidenten während der Umbruchszeit, dem es allerdings anschließend nie gelungen war, Staatspräsident zu werden. Ihm zur Seite stehen der frühere Außenminister Algirdas Saudargas und eine Nachwuchspolitikerin, die erst 25-jährige Radvile Morkünaitè. Unter den Schwergewichten befinden sich jedoch auch fragwürdige Personen der litauischen Politik, so etwa der durch ein Amtsenthebungsverfahren nach einem Verfassungsbruch abgesetzte frühere Präsident Rolandas Paksas und Viktor Uspaskich, der auch nach seiner Rückkehr aus Russland nach wie vor unter Korruptionsverdacht steht. Der litauische Seimas hatte ihm im Dezember 2008 deshalb die Immunität entzogen.

\begin{tabular}{|l|c|c|l|}
\hline Tabelle 7: Die Wahl zum EP 2009 in Litauen \\
\hline Partei & $\begin{array}{c}\text { Stimmen } \\
\text { (in Prozent) }\end{array}$ & Mandate & EP Fraktion \\
\hline Heimatunion - Litauens Konservative & 26,86 & 4 & EPP \\
Sozialdemokratische Partei Litauens & 18,61 & 3 & S\&D \\
Partei Ordnung und Gerechtigkeit & 12,22 & 2 & EFD \\
Arbeitspartei & 8,71 & 1 & ALDE \\
Litauens Wahlaktion der Polen & 8,42 & 1 & ECR \\
Liberale Union der Republik Litauen & 7,36 & 1 & ALDE \\
\hline
\end{tabular}

Quelle: http://www.europarl.europa.eu/parliament/archive/elections2009/de/lithuania_de.html (Abruf am 17. Januar 2011). 


\section{Parteiensystem oder Anti-Parteiensystem?}

Die Entwicklung der Parteiensysteme in den postsozialistischen Staaten Osteuropas, darunter auch die baltischen, ermöglicht der Politikwissenschaft, zwingt sie geradezu zu einer neuen Fragestellung. Während man im Westen beobachten kann, wie sich bottom-up Parteien über die Jahrzehnte zu Volksparteien, Catch All Parties ${ }^{21}$ bis hin zu professionellen Wählerparteien ${ }^{22}$ herausgebildet haben, kann nunmehr zwischen Estland und Bulgarien beobachtet werden, wie sich von top-down Parteien dominierte Systeme entwickeln. Aber das ist eine oberflächliche Charakterisierung, die sich noch an die Theorien der Parteienforschung vor der Transformation klammert.

Mit der Cleavage-Theorie ${ }^{23}$ war versucht worden, die Herkunft der Parteien zu erklären in einer Zeit, als die ersten freien Wahlen in vielen der analysierten Staaten nicht einmal ein halbes Jahrhundert zurück lagen, mehrere Staaten durch autoritäre Phasen gegangen waren und vor allem auch der Zweite Weltkrieg einen Bruch dargestellt hatte, also vor den gesellschaftlichen Veränderungen Ende des 20. Jahrhunderts. Bis dahin unterscheidet sich die Entwicklung im Baltikum nur darin, dass die Folgen des Zweiten Weltkrieges ein halbes Jahrhundert lang in einem Aussetzen der demokratischen Entwicklung mündeten.

50 Jahre Sowjetherrschaft hinterließen eine weitgehend nivellierte Gesellschaft, in denen klassische Cleavages wie Arbeit und Kapital sowie Glaubensfragen kaum existierten, dafür aber ein handfester ethnischer Konflikt zwischen den Titularnationen und den „Besatzern“. Darum gab es, nachdem auch in der Sowjetunion etwas anderes als die Linie der KP plötzlich erlaubt war, in den baltischen Ländern ein Viereck politischer Kräfte: Gegner und Befürworter der Unabhängigkeit, die sich jeweils in einen moderaten und einen radikaleren Flügel spalteten. Die radikalen Protagonisten des Sowjetregimes waren in Litauen schwach. Die Befürworter der Unabhängigkeit waren ihrerseits deutlich geeinter, weshalb sich in Litauen keine Nationale Unabhängigkeitspartei neben dem Sąjūdis konstituierte. Damit existierte ab 1988 mit der Gründung der Unabhängigkeitsbewegungen de facto ein Mehrparteiensystem. ${ }^{24}$ Valdis Blüzma schränkt ein, es habe sich bei diesen Kräften keineswegs um Parteien gehandelt, weil sie weniger orientiert auf die Machterlangung waren und sich vielmehr als Protestbewegungen verstanden. Dem ist entgegenzuhalten, dass sie sich an Wahlen beteiligten und / oder solche selbst organisierten. Die lettische Volksfront war am ehesten nur bedingt eine Partei, weil sie beispielsweise Mehrfach-Mitgliedschaften zuließ. ${ }^{25}$

Durch die ökonomische Entwicklung der 1990er Jahre wurde besonders ein Gegensatz zwischen Zentrum und Peripherie virulent, der sich jedoch nur begrenzt im Parteienspektrum niederschlug; so blieb die ländliche Volksunion in Estland immer eine Splitterpartei,

21 Vgl. Otto Kirchheimer, Der Wandel des westeuropäischen Parteiensystems, in: PVS, 6. Jg. (1965), H. 1, S. $20-41$.

22 Vgl. Klaus von Beyme, Parteien im Wandel. Von den Volksparteien zu den professionalisierten Wählerparteien, Opladen 2000.

23 Vgl. Seymour Martin Lipset / Stein Rokkan, Party Systems and Voter Alignments. Cross-National Perspectives, New York 1967.

24 Toomla als wichtigster Parteienexperte Estlands sieht 1988 ein Viereck aus Kommunisten, Volksfront, Interfront und Nationalisten. Vgl. Rein Toomla, Eesti erakonnad, Tallinn 1999, S. 199.

25 Vgl. Valdis Blūzma, Politisko partiju veidošanās Latvijā pirmsākumi, in: Latvijas Zinātnu akadēmijas Baltijas stratēégisko pētījumu centrs (Hrsg.), Latvijas Universitātes žurnāla „Latvijas Vēsture“ fonds. Latvijas valsts atjaunošana 1986-1993, Riga 1998, S. 260. 


\begin{tabular}{|c|c|}
\hline \multicolumn{2}{|c|}{ Abbildung 1: Der Ursprung der baltischen Parteiensysteme } \\
\hline $\begin{array}{l}\text { Volksfronten } \\
\text { Eesti Rahvarinne(Estland) } \\
\text { Latvijas Tautas Fronte (Lettland) } \\
\text { Sajūdis (Litauen) }\end{array}$ & 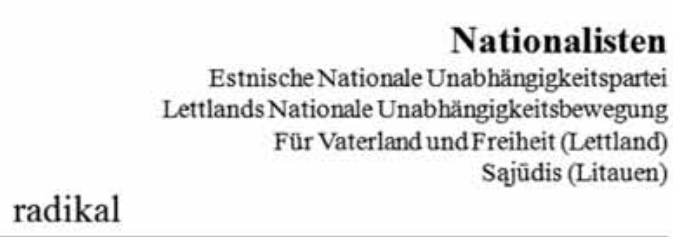 \\
\hline $\begin{array}{l}|\downarrow| \\
\text { Reformkommunisten } \\
\text { Freies Estland } \\
\text { LDDP(Litauen) }\end{array}$ & $\begin{array}{r}\text { Interfronten } \\
\text { Interbewegung (Estland) } \\
\text { Interfront(Lettland) } \\
\text { Einheit (Litauen) }\end{array}$ \\
\hline
\end{tabular}

während die Bauernunion in Lettland auch die städtische Wählerschaft anspricht. Dafür verantwortlich ist wesentlich deren graue Eminenz, der Bürgermeister der Hafenstadt Ventspils, deren Einwohner ihre Interessen üblicherweise bei Liberalen vertreten sehen müssten, nicht bei einer Bauernpartei, die überdies mit den Grünen in Fraktionsgemeinschaft zusammenarbeitet.

Dieses Paradoxon demonstriert, dass sich die Menschen in Ermangelung einer sozioökonomisch dem Westen vergleichbaren Gesellschaft nicht an politisch-ideologischen Begriffen des Westens orientieren; diese werden oft nicht verstanden und sind unbedeutend, weshalb zahlreiche Parteien völlig unpolitische Namen wie Neue Zeit oder Res Publica wählen, die eine Einordnung im Spektrum schwierig machen. Bedeutend sind, wie in den vergangenen 20 Jahren in unzähligen Publikationen immer wieder betont wurde, Personen. ${ }^{26}$

Die Cleavage-Theorie kann also die baltischen Parteiensysteme in ihrer Entstehung nicht erklären und liefert auch keine Hilfe bei der weiteren Entwicklung, denn besonders in Lettland, partiell aber auch in Litauen sind die Parteien instabil, von Spaltungen und Fusionen geprägt, die sich ihrerseits an Popularitätswerten mehr orientieren als an Inhalten. So ist es nach wie vor kein unübliches Phänomen, dass im Laufe der Wahlperiode Abgeordnete die Parteizugehörigkeit wechseln, was als „party hopping“ bezeichnet wurde. ${ }^{27} \mathrm{Um}$ dagegen vorzugehen, hatte sich die Neue Zeit 2002 einen Schwur im Rigaer Dom ausgedacht, der allerdings die Erosion der Partei nicht aufhielt. Die Volkspartei bot ihren Kandidaten 1998 die Unterschrift unter ein Dokument an, dass der Wahlkampf pro erfolgreichen Kandidaten 25.000 Lat gekostet hat. ${ }^{28}$

26 Nach Ansicht von Auers und Ikstens wird dies befördert durch die lose gebundenen Listen, die dem Wähler erlauben, auch die Fraktionszusammensetzung zu bestimmen, weshalb die Parteien auch gezielt mit Personen werben. Vgl. Daunis Auers / Jānis Ikstens, Politisko partiju demokrātiskā loma, in: dies. (Hrsg.), Cik demokrātiskā ir Latvija. Demokrātijas audits, Riga 2005, S. 93.

27 Bernard Grofman / Evald Mikkel / Rein Taagepera, Fission and Fusion of Parties in Estonia, in: Journal of Baltic Studies, 31. Jg. (2000), H. 4, S. 329 - 357, S. 349.

28 Vgl. Daunis Auers / Jānis Ikstens, a.a.O. (Fn. 26), S. 94. 
So gibt es trotz sozialer Probleme nach wie vor in keinem der drei baltischen Länder eine Partei, die „den kleinen Mann“ anspricht. Eine erwähnenswerte sozialdemokratische Partei gibt es überhaupt nur in Litauen. Die estnische gleichnamige Partei hat hingegen regelmäßig mit den Marktliberalen koaliert.

Ein noch älteres Modell für die Entstehung von Parteien ist Maurice Duvergers These von der bottom-up und top-down Entstehung. ${ }^{29}$ Dabei ist bislang nicht diskutiert worden, ob die Volksfronten als Regenschirm-Bewegungen nun aus dem Volke entstanden sind. Eher mag dies noch auf die national orientierten Kräfte zutreffen, die in Estland mit großem und in Lettland mit mäßigem Erfolg sogar 1990 Gegenparlamente zu den jeweiligen Obersten Sowjets etablieren konnten, deren Wahlen sie boykottierten. In Estland bildete diese Versammlung später sogar gemeinsam mit dem sowjetischen Haus die verfassungsgebende Versammlung. Sicher ist jedoch, dass im Rahmen der zahlreichen Spaltungen alle Parteien Gründungen der politischen, ökonomischen oder teilweise sogar medialen Eliten waren. Gewiss gab es in der Anfangseuphorie oft Zulauf nicht nur von Karrieristen, die auf eine politische Kraft hofften, die endlich mit den Zuständen im Lande aufräumte. Getragen von der geringen Anforderung von nur 200 Gründungsmitgliedern in Lettland ist eine Parteigründung jedoch sehr einfach. Und so handelt es sich im Sinne von Duverger eigentlich meistens nicht um top-down Parteien, denn eine breite Basis fehlt beinahe allen: Sie sind somit top-Parteien geblieben.

In Osteuropa und besonders in Lettland sind aber die Parteien nicht nur unfähig zur Rekrutierung neuer Mitglieder, da in der Bevölkerung jegliches Vertrauen verspielt wurde. Sie bemühen sich hier nicht einmal - mehr noch, sie haben geradezu ein Interesse daran, mitgliederschwache Parteien zu bleiben, um den innerparteilichen Einfluss von einfachen Mitgliedern zu minimieren. So gibt es in Lettland zahlreiche Parteien, die wie die Neue Zeit eine Empfehlung von zwei Parteimitgliedern für die Aufnahme verlangen oder Für Vaterland und Freiheit sowie die Grünen, die überhaupt nur Staatsbürger aufzunehmen bereit sind. ${ }^{30}$

Innerparteiliche Demokratie ist nicht erwünscht, weshalb von oligarchischen Strukturen zu sprechen hier sicher berechtigt ist. Viele Menschen wissen aus ihrem Bekanntenkreis zu berichten, dass der Versuch eines politischen Engagements in der Partei nicht gern gesehen wurde. ${ }^{31}$ Eine Untersuchung des lettischen Ablegers von Transparency International, Delna, belegt, dass nicht nur die Entscheidungen über die Kandidaten und deren Positionen regelmäßig im kleinen Kreis unter Einflussnahme der Geldgeber getroffen werden, sondern die einfachen Parteimitglieder weder zur Kritik an Verfahren und aufgestellten Personen bereit sind, noch dazu, selbst zu kandidieren. Somit gibt es nur wenige Parteien, die eine Mitgliedschaft zur Voraussetzung für eine Kandidatur machen. Andere suchen statt unbekannten Parteimitgliedern lieber bekannte Persönlichkeiten. ${ }^{32}$

Beobachtbar ist dies jedoch auch bei Spitzenpolitikern, die im Falle steigender Popularität entweder am weiteren Aufstieg in der Partei gehindert werden und sich dann eine andere Plattform suchen oder aber auch schon einmal sogar in Abwesenheit aus der Partei aus-

29 Vgl. Maurice Duverger, Die politischen Parteien, Tübingen 1959.

30 Vgl. Daunis Auers / Jānis Ikstens, a.a.O. (Fn. 26), S. 89.

31 Vgl. ebenda, S. 95.

32 Vgl. Delna (Hrsg.), Cik demokrātiskas ir Latvijas politiskās partijas? Vēlēšanu sarakstu veidošana pirms 2009. Gada pašvaldību vēlēšanām, Riga 2009. 
geschlossen und als Minister abgesetzt werden, wie im Falle von Aigars Štokenbergs 2007. Neben diesen Beobachtungen ist festzustellen, dass es eigentlich nie Konkurrenz um Führungsämter gibt. Die frühere wichtigste Regierungspartei Lettlands Weg erlebte 2000 eine Kampfkandidatur um den Vorsitz wie auch die konservative Für Vaterland und Freiheit. Kandidat Girts Valdis Kristovskis kündigte 2008 den Parteiaustritt für den Fall an, dass er nicht gewählt würde. Er unterlag dann dem EP-Abgeordneten Roberts Zïle und wechselte die Partei.

Die Ursache liegt in einem nicht nur weit verbreiteten, sondern auch anhaltenden Missverständnis des Politischen schlechthin, das sich nicht nur in der Durchschnittsbevölkerung $^{33}$ hartnäckig hält, sondern partiell auch bei Politikwissenschaftlern an Universitäten, in Nachrichtenagenturen oder demoskopischen Instituten. So ist die Bewertung des Wahlergebnisses in Lettland durch die einheimischen Politologen Puriņ̌̌ und Šulcs überraschend: Gemeinsam sprechen sie davon, dass Sozialdemokraten im lettischen Parteienspektrum nicht angeboten würden ${ }^{34}$ und weisen damit die Aufgabe, eine Parteienlandschaft aufzubauen, der Elite zu, als könne es nur top-down Parteien geben. Solchen Beurteilungen liegt eine der Bevölkerung vergleichbar negative Rezeption des politischen Prozesses zugrunde. So bezeichnet beispielsweise Curika ${ }^{35}$ den Konflikt der Parteien um Macht und Einfluss als Erpressung, wenn eine konkrete politische Kraft von einer anderen während der Koalitionsverhandlungen etwa ein Zugeständnis bezüglich konkreter Ressorts in der Regierung verlangt. Curika hält es auch für Erpressung, wenn Koalitionspartner sich bereits auf einen Ministerpräsidentenkandidaten geeinigt haben, bevor sie sich zum ersten Mal mit dem Präsidenten treffen, der gemäß der Verfassung das Recht zur Benennung eines Kandidaten für dieses Amt hat. ${ }^{36}$

Nach den vorangegangenen Wahlen zu den vierten Parlamenten des Baltikums und im 13. Lebensjahr der wieder gewonnenen Unabhängigkeit lässt sich schließen, dass die neuen Demokratien aus der „Pubertät“ noch nicht ganz heraus sind, wie vor allem das Beispiel Rep̌se in Lettland belegt. ${ }^{37}$ Dennoch gibt es deutliche Unterschiede. So hat sich zwar inzwischen in Estland ${ }^{38}$ eine gewisse Stabilität eingestellt, während das Parteiensystem in Lettland durch Fluidität gekennzeichnet ist. ${ }^{39}$ Aber Lettland hat mit seiner Staatlichkeit an sich

33 Vgl. Axel Reetz / Veiko Spolitis, Die Sehnsucht des Volkes nach einer unschuldigen Politik, in: Axel Reetz (Hrsg.), Aktuelle Probleme postsozialistischer Länder. Das Beispiel Lettland, Wittenbach 2007, S. $134-146$.

34 Vgl. Gatis Puriņš / Uğis Šulcs, 9. Saeima: Labējā nestabilitāte, http://www.politika.lv/temas/ 11917/ (Abruf am 17. Januar 2011).

35 Linda Curika hatte zu diesem Thema unter der Betreuung der lettischen Politikwissenschaftlerin Ilze Ostrovska eine Magisterarbeit geschrieben. Sie arbeitete zum Zeitpunkt der Veröffentlichung des erwähnten Beitrages bei Providus, einem von der Soros-Stiftung finanzierten Institut für politische Forschung.

36 Vgl. Linda Curika, Koalīciju veidošanas labirinti, http://www.politika.lv/index.php?id=11905 (Abruf am 17. Januar 2011).

37 Vgl. Axel Reetz, Die vierten Parlamente in Estland, Lettland und Litauen: Ähnliche Voraussetzungen, verschiedene Pfade, in: ZParl, 36. Jg. (2005), H. 2, S. 326 - 347.

38 Vgl. Rein Toomla, a.a.O. (Fn. 24), S. 256.

39 Vgl. Axel Reetz, Baltische Staaten. Politiker als Fixpunkte und verschiedene Varianten von parteipolitischer Fluidität, in: Ellen Bos / Dieter Segert (Hrsg.), Osteuropäische Demokratien als Trendsetter? Parteien und Parteiensysteme nach dem Ende des Übergangsjahrzehnts, Opladen / Farmington Hills 2008, S. 229 - 252. 
nach wie vor schwere Probleme 90 Jahre nach der ersten Staatsgründung, von denen in Unabhängigkeit nur 39 genossen wurden, 17 davon jüngst und demzufolge 33 unter demokratischer Herrschaft. ${ }^{40}$ Es ist darum paradox, dass gerade in Estland mit den Grünen und in Litauen mit der Partei der Nationalen Wiedergeburt, hingegen in Lettland keine neue Partei zu den Wahlen angetreten ist. Das litauische Beispiel erinnert auf den ersten Blick an die Unabhängigen Royalisten in Estland des Jahres 1992 und damit auch an David Arters „Anti-Parteien“ “41, womit er beschreiben wollte, dass die politischen Kräfte sich nicht gern als Parteien sehen und benennen wegen der schlechten Reputation in der Bevölkerung. Doch die Partei verdankt ihren Erfolg wie die Grünen in Estland dem Wunsch des Wählers nach etwas Unverbrauchtem. Beide Parteien waren sofort zur Übernahme politischer Verantwortung in Form einer Regierungsbeteiligung bereit, was sich in Estland wegen der Mehrheitsverhältnisse zerschlug.

In Lettland kam es hingegen infolge der Regenschirmrevolution durch die Abspaltungen von der Volkspartei (Gesellschaft für eine andere Politik) und der Neuen Zeit (Bürgerliche Union) zu einer neuerlichen Umgruppierung innerhalb der politischen Elite. Dagegen gibt es in Estland und Litauen eine Tendenz zu Konzentrationen rund um die - zufällig (?) gleich benannte - jeweilige Vaterlandsunion.

Hoffnungen auf eine konkrete politische Verortung in bekannten Schemata von Seiten der Wähler und der politischen Elite als spill over Effekt der Mitarbeit in Fraktionen des Europäischen Parlaments haben sich hingegen während der letzten Jahre nicht erfüllt. Im Gegenteil kann die Politikwissenschaft in letzter Zeit eher auch im Westen Phänomene beobachten, die dem Osten früher als Defekte in der Demokratie vorgeworfen wurden. In den baltischen Staaten gelingt es den Parteien nicht, „Wurzeln im Volk zu schlagen“, ja sie bemühen sich darum nicht einmal, wo sie diese im Westen zunehmend verlieren. Vor allem in Lettland fehlte es in den vergangenen zwanzig Jahren fast vollständig an good governance ${ }^{42}$, doch die Bevölkerung ist weder bereit, ihre politische Elite zur Verantwortung zu ziehen, noch selbst diese zu übernehmen. ${ }^{43}$ Dies führt zu dem Paradoxon, dass bei der Suche nach einer „sauberen“ politischen Führungsfigur immer wieder für dieselben Personen gestimmt wurde und es so in den 1990er Jahren nicht zu einem Austausch der politischen Elite kam - wie etwa in Estland, wo die erste Regierung nicht nur ein sehr junges Durchschnittsalter hatte, sondern auch bewusst mit der Parole "plats puhtaks" angetreten war. ${ }^{44}$

40 Vgl. Axel Reetz / Veiko Spolìtis, Latvijas deviņdesmita un trīsdesmit trešā gadskārta, in: Akadēmiskā Dzīve, 44. Jg. (2008), S. 21 - 29.

41 David Arter, Parties and Democracy in the Post-Soviet Republics: The Case of Estonia, Aldershot 1996, S. 238.

42 Vgl. Axel Reetz, Šķēršsi “good governance” realizēšanai Latvijā. Cilvēks, sabiedrība, valsts mūsdienu mainīgajos ekonomiskajos apstākḷos: BAT 11. starptautiskās zinātniskā konference: Rakstu krājums, Rìga 2010.

43 Vgl. Axel Reetz / Veiko Spolitis, SIA Latvija, in: Cita diena vom 10. November 2009.

44 Die direkte Übersetzung dieser Parole lautet „den Platz säubern“. Sie wurde von Meri schon vorher als Außenminister in der Regierung Savisaar am radikalsten umgesetzt, indem er bei Amtsantritt 1990 die damals knappe Besetzung des Ministeriums von zehn Personen komplett entließ und sich mit neuen Mitarbeitern umgab. Vgl. Mart Laar / Urmas Ott / Sirje Endre, Teine Eesti, Tallinn 2000, S. 677. 
Folglich stellt sich die Frage, ob der Osten, wie Adam Pzreworski 1991 prophezeite, zum Süden anstelle zum Westen geworden ist ${ }^{45}$ und / oder nicht zum Trendsetter auch für die etablierten Demokratien. Dabei bieten die baltischen Republiken drei verschiedene Modelle: In Estland gibt es einen Dualismus zwischen den Parteien; die liberale Reformpartei und die konservative Vaterlandsunion / Res Publica werden von jenem Teil der Wählerschaft unterstützt, die zum Weg der vergangenen 20 Jahre keine Alternative sehen und davon weitgehend auch profitiert haben. Daneben existiert die Reformpartei als starke politische Kraft, die das russische Elektorat integriert und auch die wirtschaftlich weniger erfolgreiche Wählerschaft anspricht. In Litauen hingegen genießen die aus den Kommunisten hervorgegangenen Sozialdemokraten ebenso wenig Ansehen wie die aus der Regenschirm-Bewegung entstandene Vaterlandsunion, die sich an der Regierung abwechseln. Neue politische Kräfte waren wenig nachhaltig. In Lettland hingegen sind die dauernden Veränderungen im Parteiensystem so umfangreich, dass ein Überblick schwerfällt. Und da es Parteienkoalitionen erlaubt ist, mit gemeinsamen Listen zu kandidieren, ist auch kein Ende dieses Wandlungsprozesses abzusehen. Die Wahlen zur 9. Saeima 2006 haben gesetzeswidrig stattgefunden, wie das Verfassungsgericht 2008 festgestellt hatte, weil mit der Volkspartei und Lettlands Erster Partei / Lettlands Weg gleich zwei Listen gegen die Deckelung der Wahlkampfausgaben verstoßen hatten. Mehr als zwei Jahre nach dem Urnengang führte dies jedoch nicht zu sofortigen Neuwahlen. Angesichts der eingetretenen Krise und der Massenproteste im Lande wurde eher über die in der Verfassung vorgesehene Möglichkeit spekuliert, das Parlament auf Anregung des Präsidenten und mit anschließendem Referendum aufzulösen. Dies geschah aber auch nicht, sondern die reguläre Neuwahl am 2. Oktober 2010 läutete die nächste Runde der Wahlen im Baltikum ein.

45 Vgl. Adam Przeworski, Democracy and the Market: Political and Economic Reforms in Eastern Europe and Latin America, Cambridge 1991.

\title{
Die schwedische Reichstagswahl vom 19. September 2010 - Zur Logik einer sich auflösenden sozialdemokratischen Hochburg
}

\author{
Sven Jochem
}

Am 19. September 2010 wählten die schwedischen Wahlbürger einen neuen Reichstag. Nur geringe Verschiebungen der Stimmenrelationen im Vergleich zu 2006 führten zu großen Konsequenzen: Erstmals konnten die rechtspopulistischen Schwedendemokraten (SD) ins Parlament einziehen. Aber auch erstmals in der Nachkriegsgeschichte wurde eine bürgerliche Koalition an der Wahlurne bestätigt. Und noch nie seit 1920 erreichte die Sozialdemokratische Arbeiterpartei Schwedens (SAP) mit 30,7 Prozent der Stimmen ein schlechteres Wahlergebnis. Am 14. November 2010 trat die Parteivorsitzende und sozialdemokratische Spitzenkandidatin Mona Sahlin von ihren Ämtern zurück und entfachte eine lebhafte Personaldiskussion. 